Supporting Information

\title{
The effects of poly(glycidyl ether) structure and ether oxygen placement on $\mathrm{CO}_{2}$ solubility
}

Caitlin L. Bentley, Tangqiumei Song, Benjamin J. Pedretti, Michael J. Lubben, Nathaniel A.

Lynd*, Joan F. Brennecke*

jfb@che.utexas.edu; 1ynd@,che.utexas.edu

Polymer characterization by proton NMR spectroscopy, size exclusion chromatography, differential scanning calorimetry and thermal gravimetric analysis is shown in Figures S1-S15. This is followed by a description of the buoyancy correction method for the gravimetric balance and of the method used to determine sample density in the gravimetric balance. Finally, the estimation of polymer density uncertainty and its impact on the Henry's law constant is discussed and additional viscosity measurements are provided.

\section{Polymer Characterization}

\section{1 ${ }^{1} \mathrm{H}$ NMR Spectra used to estimate polymer purity}

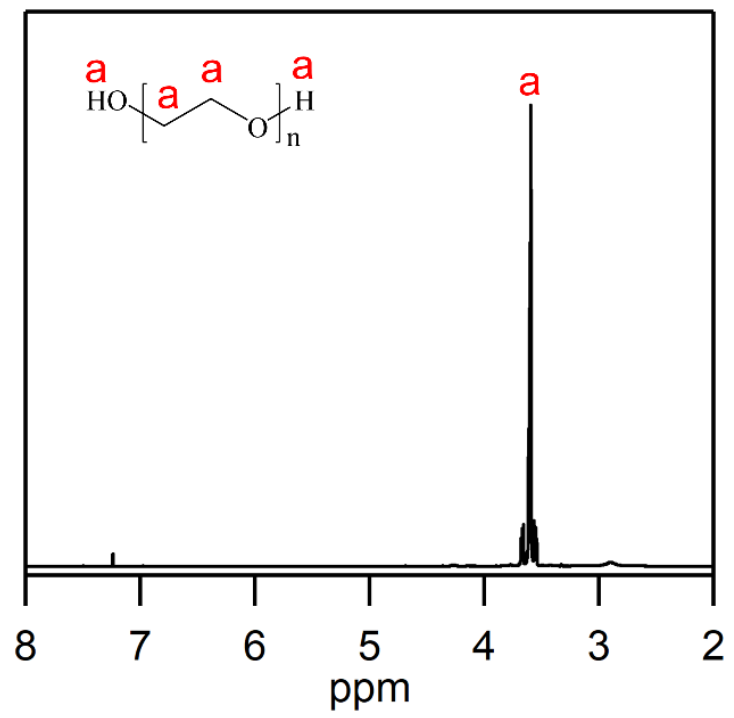

Figure S1. ${ }^{1} \mathrm{H}$ NMR spectrum $\left(\mathrm{CDCl}_{3}\right)$ of poly(ethylene oxide) 


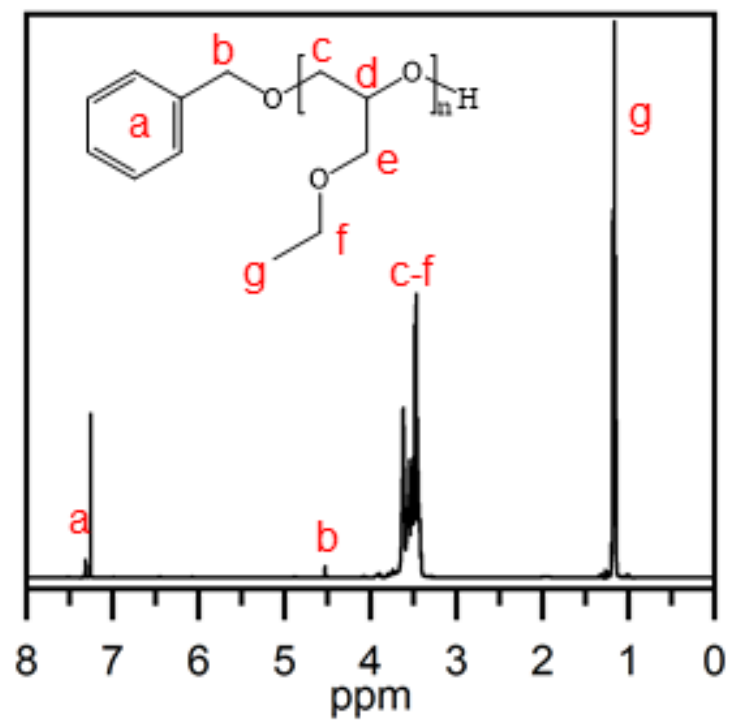

Figure S2. ${ }^{1} \mathrm{H}$ NMR spectrum $\left(\mathrm{CDCl}_{3}\right)$ of ca. $600 \mathrm{~g} / \mathrm{mol}$ poly(ethyl glycidyl ether)

Reproduced from Bentley, C. L.; Chwatko, M.; Wheatle, B. K.; Burkey, A. A.; Helenic, A.; Morales-Collazo, O.; Ganesan, V.; Lynd, N. A.; Brennecke, J. F., Modes of interaction in binary blends of hydrophobic polyethers and imidazolium bis(trifluoromethylsulfonyl)imide ionic liquids. Macromolecules. 2020, 53, (15), 6519-6528.

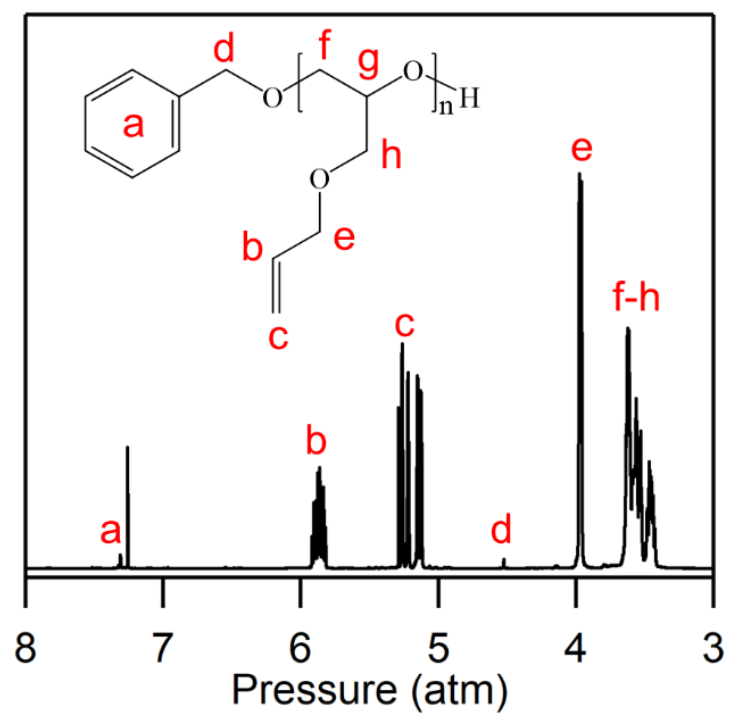

Figure S3. ${ }^{1} \mathrm{H}$ NMR spectrum $\left(\mathrm{CDCl}_{3}\right)$ of poly(allyl glycidyl ether) 


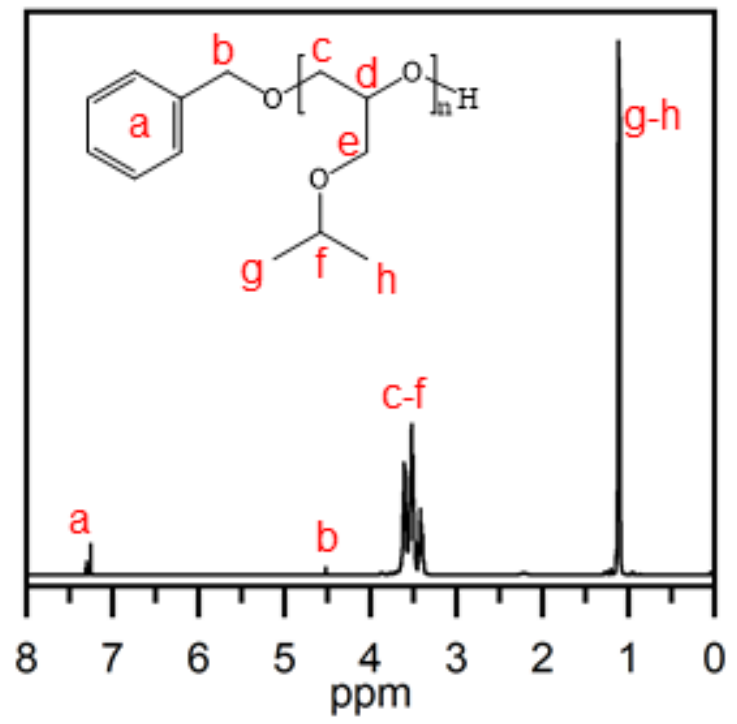

Figure S4. ${ }^{1} \mathrm{H}$ NMR spectrum $\left(\mathrm{CDCl}_{3}\right)$ of poly(iso-propyl glycidyl ether)

Reproduced from Bentley, C. L.; Chwatko, M.; Wheatle, B. K.; Burkey, A. A.; Helenic, A.; Morales-Collazo, O.; Ganesan, V.; Lynd, N. A.; Brennecke, J. F., Modes of interaction in binary blends of hydrophobic polyethers and imidazolium bis(trifluoromethylsulfonyl)imide ionic liquids. Macromolecules. 2020, 53, (15), 6519-6528.

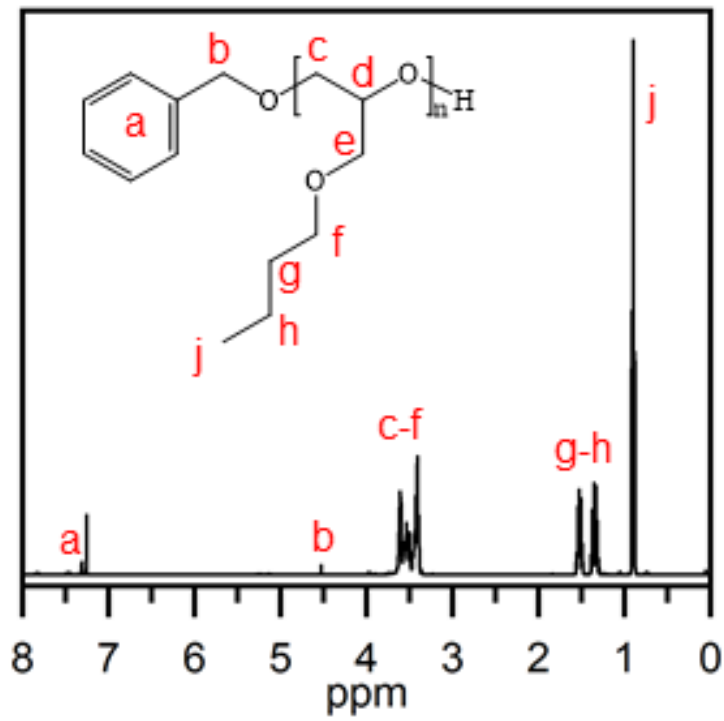

Figure S5. ${ }^{1} \mathrm{H}$ NMR spectrum $\left(\mathrm{CDCl}_{3}\right)$ of $\operatorname{poly}(n$-butyl glycidyl ether $)$

Reproduced from Bentley, C. L.; Chwatko, M.; Wheatle, B. K.; Burkey, A. A.; Helenic, A.; Morales-Collazo, O.; Ganesan, V.; Lynd, N. A.; Brennecke, J. F., Modes of interaction in binary 
blends of hydrophobic polyethers and imidazolium bis(trifluoromethylsulfonyl)imide ionic liquids. Macromolecules. 2020, 53, (15), 6519-6528.

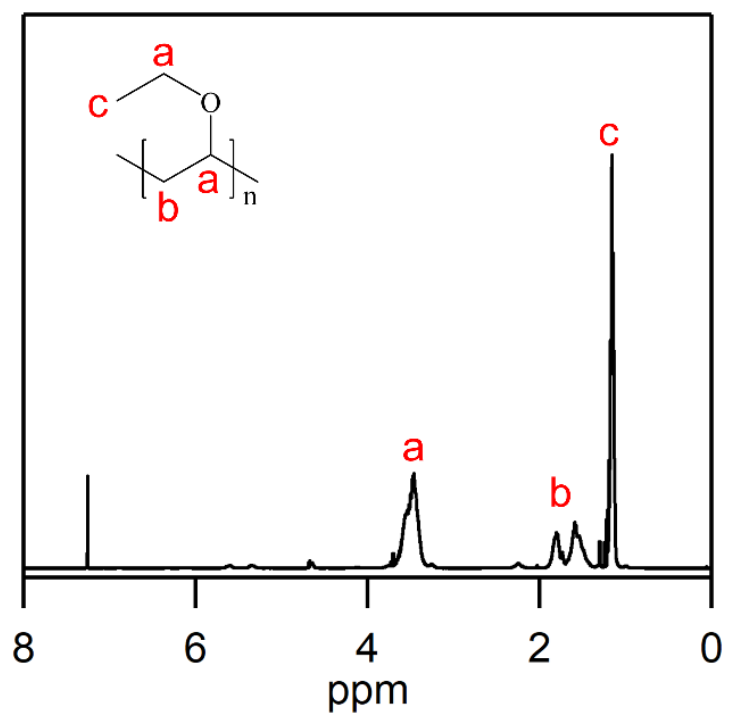

Figure S6. ${ }^{1} \mathrm{H}$ NMR spectrum $\left(\mathrm{CDCl}_{3}\right)$ of poly(ethyl vinyl ether) 


\subsection{SEC traces to determine polymer molecular weight}

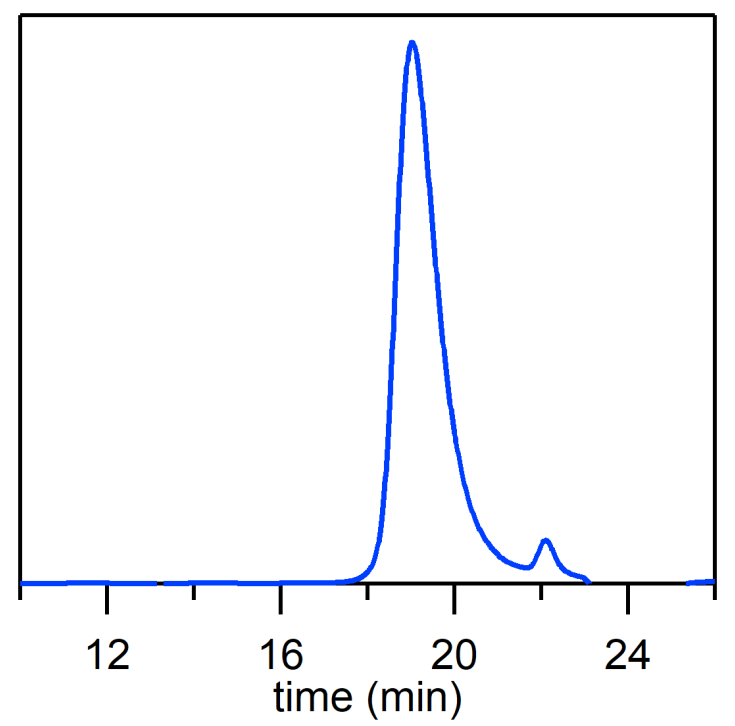

Figure S7. Gel permeation chromatograph RI trace of poly(ethylene oxide) (ca. $400 \mathrm{~g} /$ ) in chloroform.

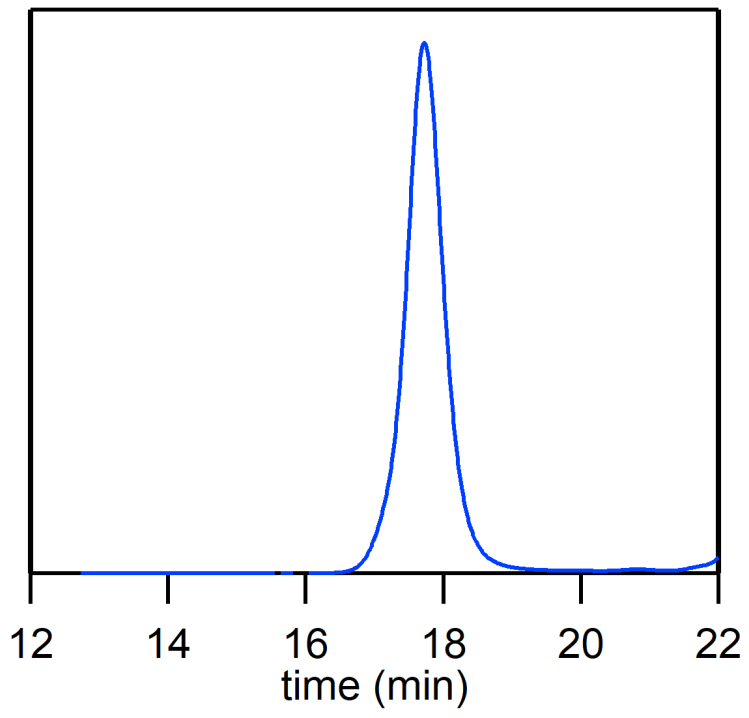

Figure S8: Gel permeation chromatograph RI trace of poly(allyl glycidyl ether) in chloroform. 


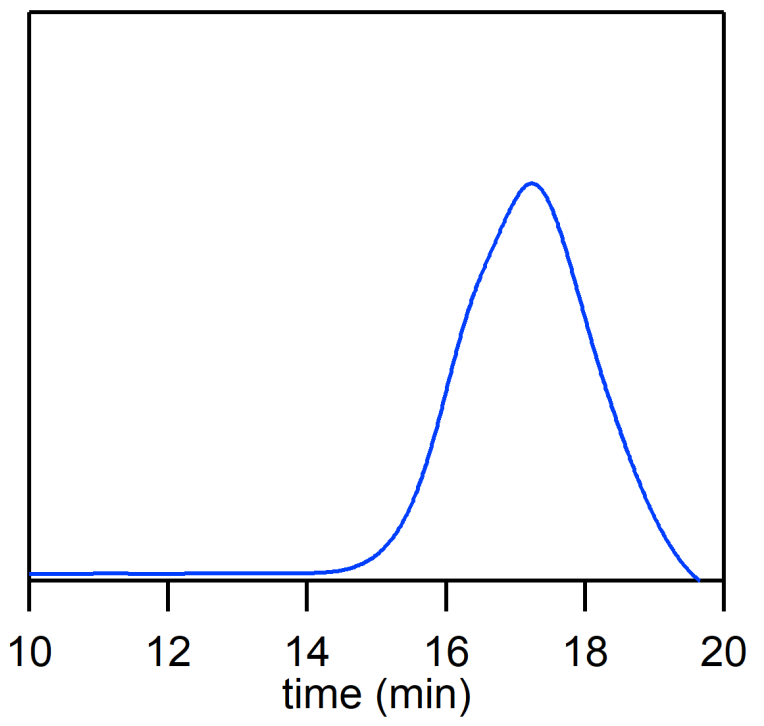

Figure S9. Gel permeation chromatograph RI trace of poly(ethyl vinyl ether) in chloroform.

SEC traces for poly(ethyl glycidyl ether), poly(iso-propyl glycidyl ether), and poly(allyl glycidyl ether) can be found in the supporting information for the following publication:

Bentley, C. L.; Chwatko, M.; Wheatle, B. K.; Burkey, A. A.; Helenic, A.; Morales-Collazo, O.; Ganesan, V.; Lynd, N. A.; Brennecke, J. F., Modes of interaction in binary blends of hydrophobic polyethers and imidazolium bis(trifluoromethylsulfonyl)imide ionic liquids. Macromolecules. 2020, 53, (15), 6519-6528. 
1.3 Thermal characterization of polymers to determine melting point, glass transition temperature, and the decomposition temperature

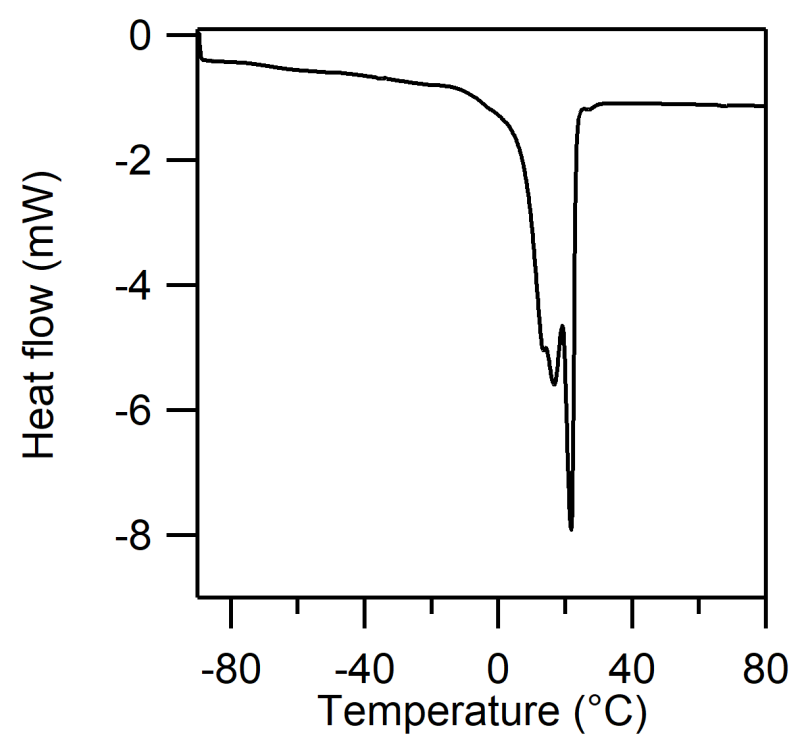

Figure S10. Differential scanning calorimetry scan of poly(ethylene oxide)

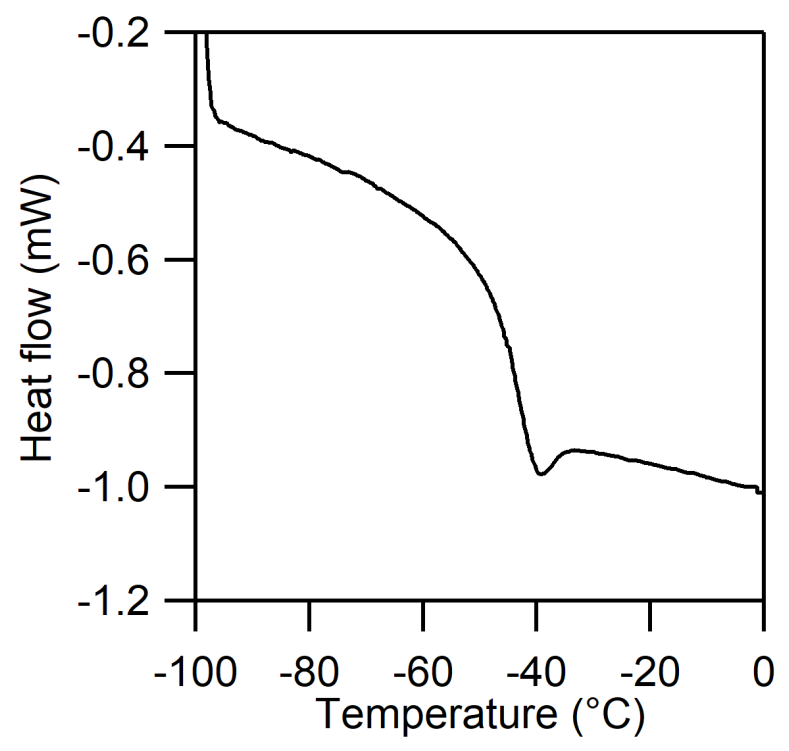

Figure S11. Differential scanning calorimetry scan of poly(ethyl vinyl ether). 


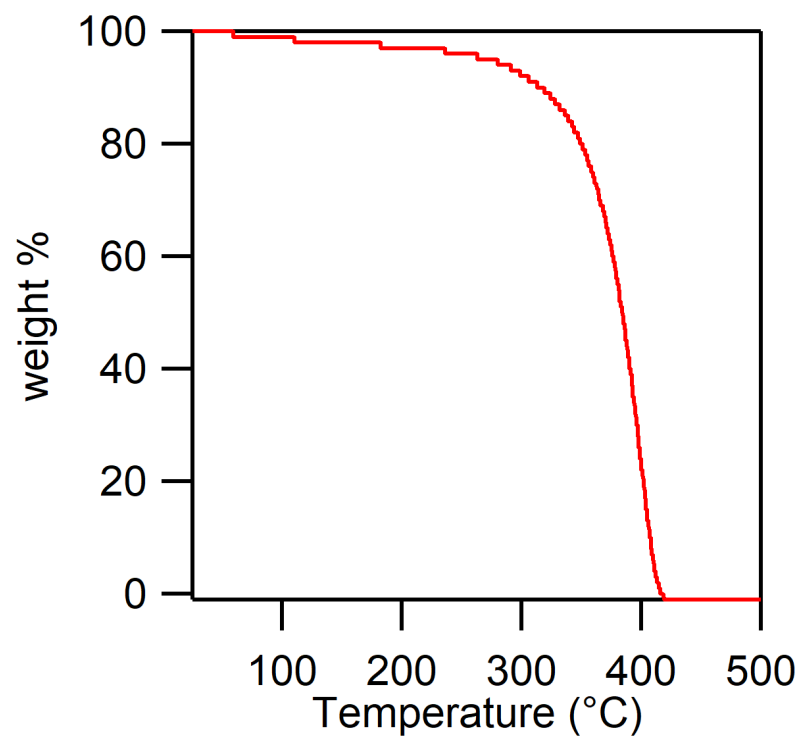

Figure S12. Thermal gravimetric analysis of poly(ethylene oxide).

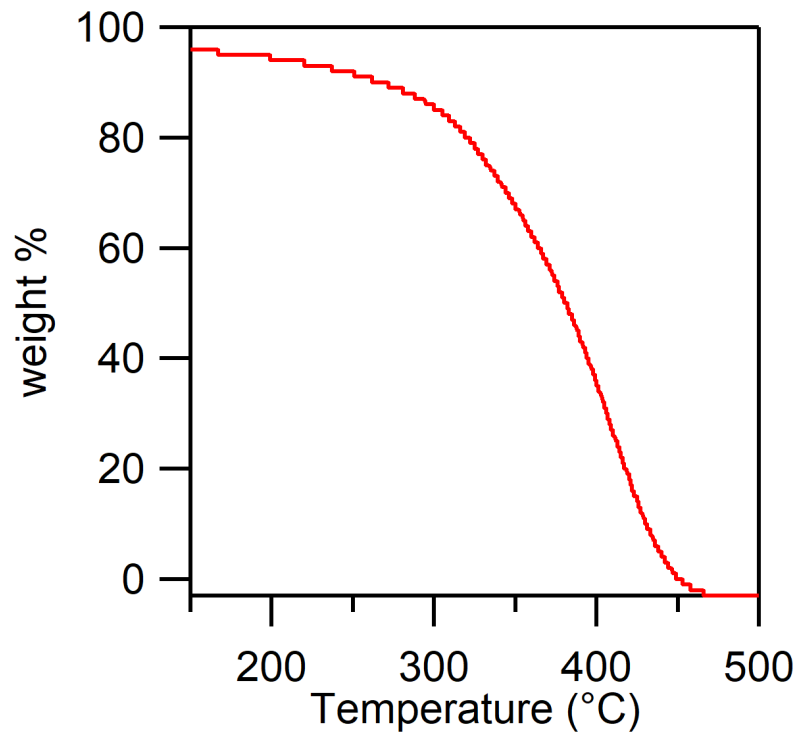

Figure S13. Thermal gravimetric analysis of poly(ethyl vinyl ether).

Differential scanning calorimetry and thermal gravimetric analysis for poly(ethyl glycidyl ether), poly(iso-propyl glycidyl ether), and poly(allyl glycidyl ether) can be found in the following publication:

Bentley, C. L.; Chwatko, M.; Wheatle, B. K.; Burkey, A. A.; Helenic, A.; Morales-Collazo, O.; Ganesan, V.; Lynd, N. A.; Brennecke, J. F., Modes of interaction in binary blends of hydrophobic 
polyethers and imidazolium bis(trifluoromethylsulfonyl)imide ionic liquids. Macromolecules. 2020, 53, (15), 6519-6528.

\section{Gravimetric sorption analysis}

\subsection{Description of the buoyancy correction}

The IGA systems (Hiden Isochema) can be represented by the simplified diagram below (Figure S14). The sample is loaded in a glass bucket which is balanced against a SS wire counterweight. The microbalance records changes in weight as gas is absorbed and buoyancy changes. The accurate determination of gas solubility relies on a correction to account for the increased buoyancy of sample and bucket as the gas pressure increases. The buoyancy correction method has been described previously. ${ }^{1,2}$ It is briefly described here since it pertains to the measurement of density gravimetrically.

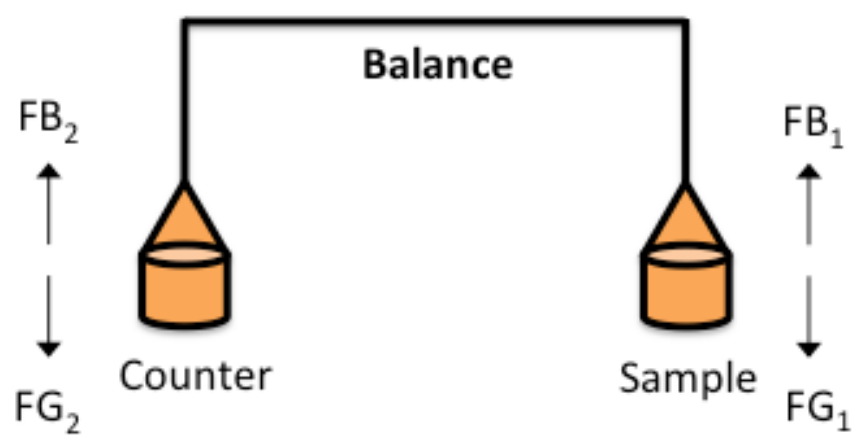

Figure S14: Free body diagram of the IGA microbalance set-up

In Figure S14 FG is the force of gravity, which is offset by FB, the buoyancy force. The weight measured by the balance is the difference between the gravitational and buoyancy forces of the sample and the counterweight (equation 1). FG and FB are described by equations (2) and (3) respectively, where $m$ is mass, $g$ is the gravitational acceleration, $\rho_{f}$ is the density of the fluid, and $V$ is volume.

$W=\left(F G_{1}-F G_{2}\right)-\left(F B_{1}-F B_{2}\right)$

$F G=m g$

$F B=\rho_{f} g V$

The buoyancy corrected mass of the sample is calculated using equation (4) where the subscript $s$ refers to the sample, 0 refers to the empty sample bucket, 2 refers to the counterweight, and $m$ refers to the measured value. Equation (4) is obtained by substitution of equations (2) and (3) in (1) and subsequent rearranging.

$m_{s}=m_{m}-\left(m_{0}-m_{2}\right)+\rho_{f}\left(V_{s}+\left(V_{0}-V_{2}\right)\right)$ 
The buoyancy correction, $\left(V_{0}-V_{2}\right)$, is obtained by measuring the empty system weight at many pressures of non-absorbing gas, like nitrogen or argon). Since the system is empty, $m_{s}$ and $V_{s}$ are equal to zero. The quantity $\left(m_{0}-m_{2}\right)$ is also equal to zero because the system is tared before each run. The negative slope of a linear fit to measured mass vs fluid density (the density of the gas in this case) is the desired quantity, $\left(V_{0}-V_{2}\right)$. The buoyancy correction is determined at each measurement temperature.

\subsection{Sample density determination by buoyancy measurement}

The density of samples can be determined in a similar way. A 50-80 mg sample is loaded into the sample bucket. A non-absorbing gas is used so that there is no change in sample mass due to gas absorption. All changes in weight are due to buoyancy changes of the sample and sample bucket. The measured mass, $m_{m}$, which now combines the sample mass and the mass of the empty bucket is related to $\left(V_{1}-V_{2}\right)$, the difference in total volume of sample bucket + sample $\left(V_{1}\right)$ and the counterweight volume by equation (5). The negative slope of a linear fit to measured mass vs fluid density is $\left(V_{1}-V_{2}\right)$.

$m_{m}=\rho_{f}\left(V_{s}+\left(V_{1}-V_{2}\right)\right)$

From the buoyancy correction we know $\left(V_{0}-V_{2}\right)$. The sample volume is calculated by equation (6) because $V_{1}=V_{0}+V_{s}$.

$V_{s}=\left(V_{1}-V_{2}\right)-\left(V_{0}-V_{2}\right)$

The sample volume is divided by the sample weight under vacuum to obtain the sample density.

The densities measured using the buoyancy technique are shown in Table S1.

Table S1: Polymer density as a function of temperature measured using the buoyancy technique

\begin{tabular}{|ccccc|}
\hline $\begin{array}{c}\text { T } \\
\mathbf{K})\end{array}$ & $\begin{array}{c}\text { PEGE-5 } \\
\left(\mathbf{g} / \mathbf{c m}^{\mathbf{3}}\right)\end{array}$ & $\begin{array}{c}\text { PiPGE-7 } \\
\left(\mathbf{g} / \mathbf{c m}^{\mathbf{3}}\right)\end{array}$ & $\begin{array}{c}\text { PAGE-11 } \\
\left(\mathbf{g} / \mathbf{c m}^{\mathbf{3}}\right)\end{array}$ & $\begin{array}{c}\text { PnBGE-7 } \\
\left(\mathbf{g} / \mathbf{c m}^{\mathbf{3}}\right)\end{array}$ \\
\hline 295 & - & 1.026 & - & 1.037 \\
333.15 & 1.068 & 0.999 & 1.062 & 1.019 \\
\hline
\end{tabular}

\section{Determination of uncertainty}

\subsection{Uncertainty in polymer density measurement}

Out of an abundance of caution, the density of PAGE was not measured using the Anton Paar DMA 4500 densitometer due to the potential for crosslinking which could damage the instrument. Therefore, three measurement techniques were used to measure polymer density: densitometer, weight of a sample of known volume, and the buoyancy technique described above.

The repeatability reported by Anton Paar for the DMA 4500 densitometer used in this work is $0.000005 \mathrm{~g} / \mathrm{cm}^{3}$, which is much lower than the estimated repeatability for the other two density measurement techniques used in this work. We conclude the most accurate density measurements 
would be provided by the DMA 4500 and that the best representation of the uncertainty in the buoyancy technique and the weighing method are the average relative deviation from the densitometer measurement. Of course, the densitometer measurements are not accurate to $\pm 0.000005 \mathrm{~g} / \mathrm{cm}^{3}$ because the samples are not $100 \%$ pure. The uncertainty of the densitometer values are estimated based on the sample purity (Table 1 in the main text) and assuming the density difference between the sample and the impurity is $10 \%$. The density measurements using the buoyancy method are reported in Table S1, the densities determined from measuring the weight of samples of known volume are in Table S2 and the densitometer measurements are in Table S3. The densities of PEGE, PiPGE and PnBGE were measured using all three techniques. The average relative deviation (ARD) of the density measurements by the buoyancy method and the weighting method compared to the densitometer values were calculated based on all measurements for PEGE, PiPGE and PnBGE according to equation 7, where $N$ is the number of measurements, $\rho$ is density measured by buoyancy or weighing, and $\rho_{d}$ is the density measurement from the densitometer. The ARD for the buoyancy technique is $4.5 \%$ and it is $2.2 \%$ for the weighing method, as shown in Table S5.

$A R D=\frac{\sum_{i=1}^{N}\left|\frac{\rho-\rho_{d}}{\rho_{d}}\right|}{N} * 100 \%$

Table S2: Polymer density at $295 \pm 1.5 \mathrm{~K}$ determined by measuring the weight of a sample of known volume

\begin{tabular}{|c|c|c|c|c|}
\hline $\begin{array}{c}\mathbf{T} \\
(\mathbf{K})\end{array}$ & $\begin{array}{c}\text { PEGE-5 } \\
\left(\mathrm{g} / \mathrm{cm}^{3}\right)\end{array}$ & $\begin{array}{c}\text { PiPGE-7 } \\
\left(\mathrm{g} / \mathrm{cm}^{3}\right)\end{array}$ & $\begin{array}{c}\text { PAGE-11 } \\
\left(\mathrm{g} / \mathrm{cm}^{3}\right) \\
\end{array}$ & $\begin{array}{c}\text { PnBGE-7 } \\
\left(\mathrm{g} / \mathrm{cm}^{3}\right)\end{array}$ \\
\hline 295 & 0.9856 & 1.013 & 1.077 & 0.9778 \\
\hline 295 & 1.009 & 1.008 & 1.071 & 0.9829 \\
\hline 295 & 0.9949 & 1.009 & 1.092 & 0.9814 \\
\hline average & 0.9966 & 1.010 & 1.080 & 0.9807 \\
\hline std. dev. & 0.0097 & 0.0022 & 0.0091 & 0.0021 \\
\hline
\end{tabular}

Table S3: Polymer density as a function of temperature measured with the Anton Paar DMA vibrating tube densitometer

\begin{tabular}{|llllll|}
\hline T/K & PEO-0.4 & PEGE-5 & PiPGE-7 & PnBGE-7 & PEVE-4 \\
\hline 295 & $1.127 \pm 0.005$ & $1.046 \pm 0.004$ & $0.999 \pm 0.005$ & $0.987 \pm 0.004$ & $0.959 \pm 0.007$ \\
313.15 & $1.113 \pm 0.005$ & - & - & - & $0.947 \pm 0.007$ \\
333.15 & $1.097 \pm 0.005$ & $1.017 \pm 0.004$ & $0.970 \pm 0.005$ & $0.960 \pm 0.004$ & $0.932 \pm 0.007$ \\
343.15 & - & $1.009 \pm 0.004$ & - & - & - \\
\hline
\end{tabular}


Table S4: Average relative deviations between weighing or buoyancy method density measurements and densitometer measurements

\begin{tabular}{|c|c|}
\cline { 2 - 2 } \multicolumn{1}{c|}{} & ARD \\
\hline Weight of sample of known volume & $2.2 \%$ \\
\hline Buoyancy method, IGA & $4.5 \%$ \\
\hline
\end{tabular}

3.2 The effect of uncertainty in density measurement on Henry's law constant calculation Sample densities are needed in order to make the buoyancy correction to the gravimetric microbalance readings in order to determine the mass of $\mathrm{CO}_{2}$ absorbed by the sample. Here we show the effect of uncertainty in the sample density on the Henry's law constants for $\mathrm{CO}_{2}$ dissolution. This is primarily a concern for PAGE, where we do not have the more accurate densitometer values of the density. The uncertainty in the density measurements of PAGE are significantly larger than the other polymers measured $\left(0.05 \mathrm{~g} / \mathrm{cm}^{3}\right.$ at room temperature and 0.02 $\mathrm{g} / \mathrm{cm}^{3}$ at $333.15 \mathrm{~K}$ ). Figures S9-10 show the isotherms corrected for buoyancy with the low, average, and high density of PAGE-11 at room temperature and $333.15 \mathrm{~K}$ using the respective density uncertainty. In all cases the uncertainty calculated from the linear regression was greater than that due to the uncertainty in density. Therefore, the linear regression uncertainty was reported.
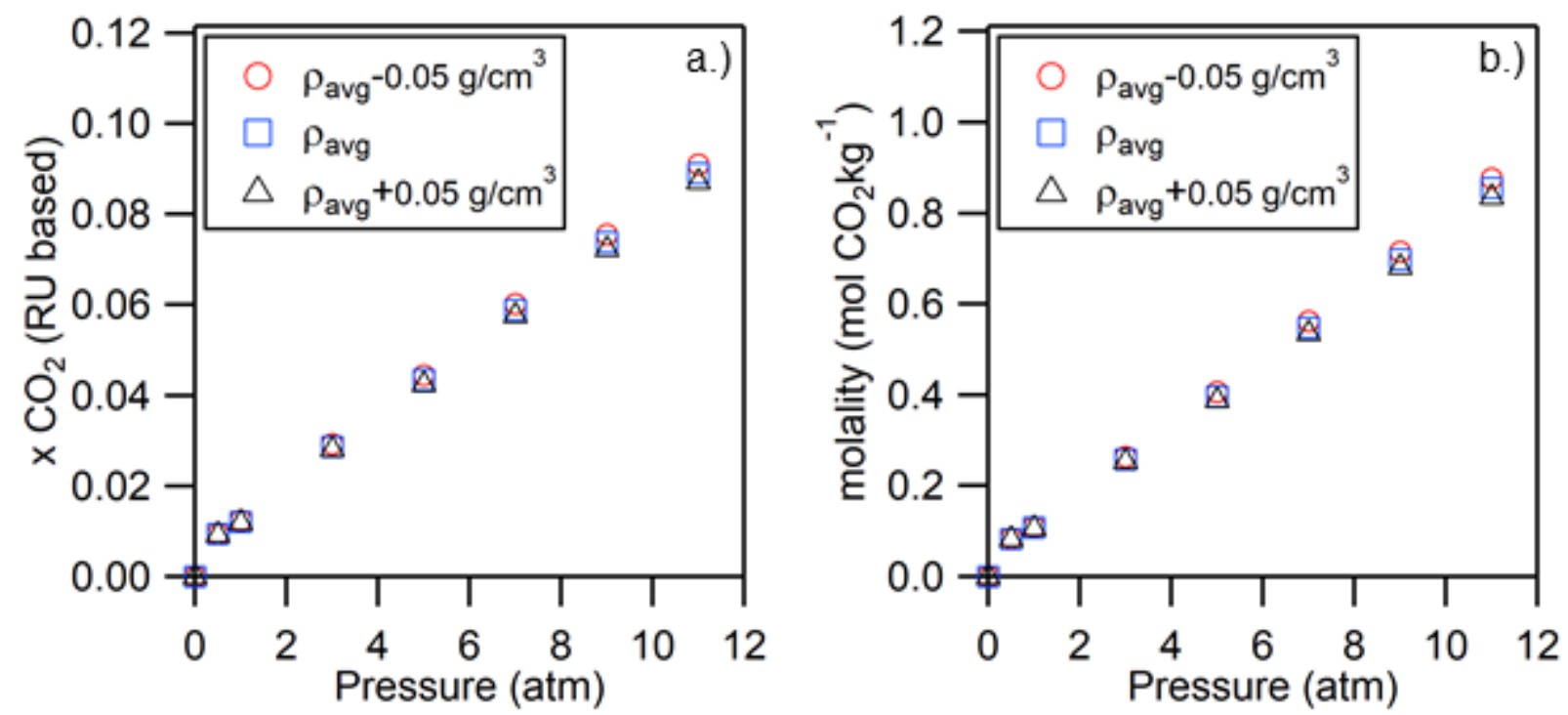

Figure S15: (a) Mol fraction of $\mathrm{CO}_{2}$ (based on mol of polymer repeat unit) in PAGE at 294.3295.4 K calculated using low, average and high densities (b) Molality of $\mathrm{CO}_{2}$ PAGE at 294.3295.4 K calculated using low, average and high densities 

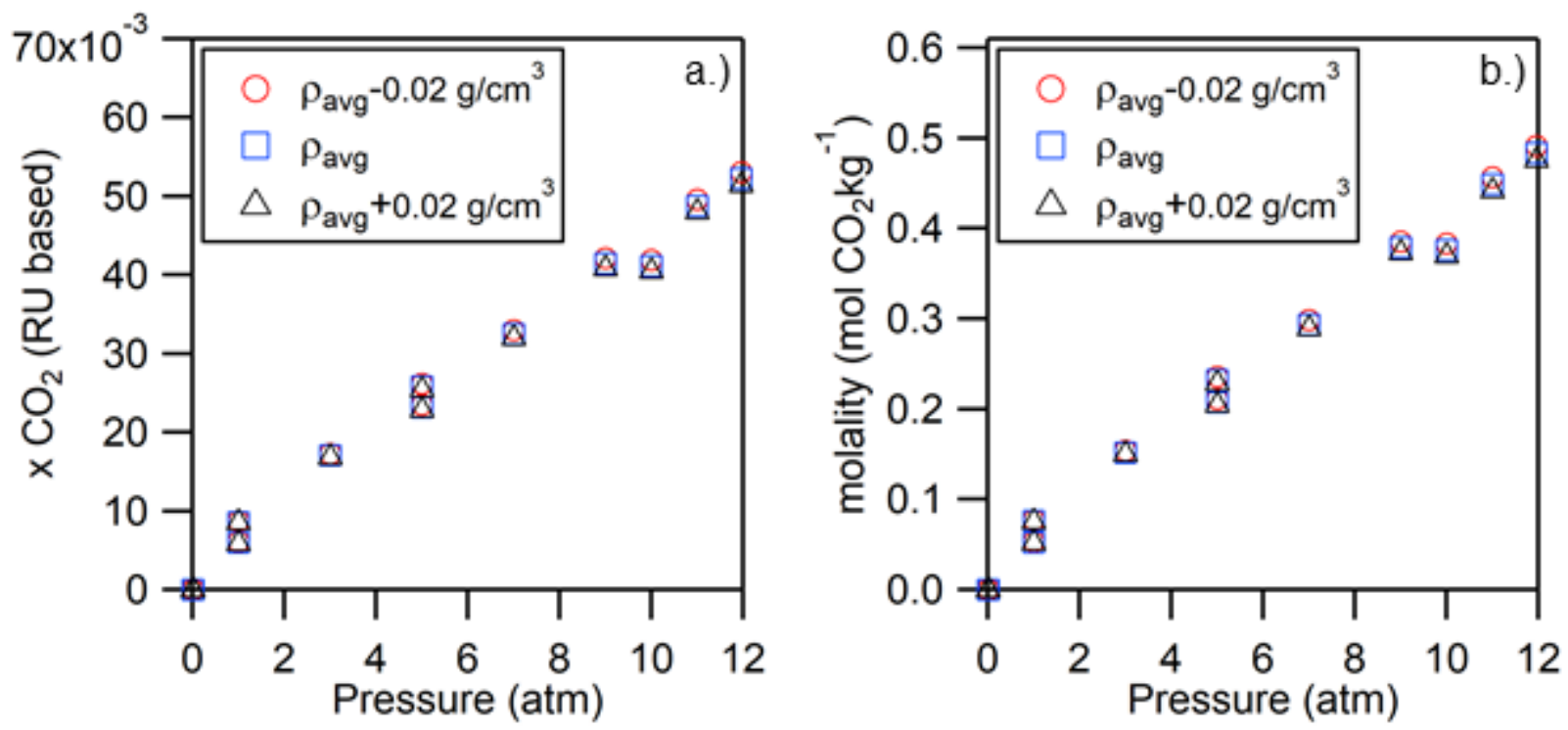

Figure S16: (a) Mol fraction of $\mathrm{CO}_{2}$ (based on mol of polymer repeat unit) in PAGE at $333.15 \mathrm{~K}$ calculated using low, average and high densities (b) Molality of $\mathrm{CO}_{2}$ PAGE at $333.15 \mathrm{~K}$ calculated using low, average and high densities 
Table S5: Temperature-dependent dynamic viscosities

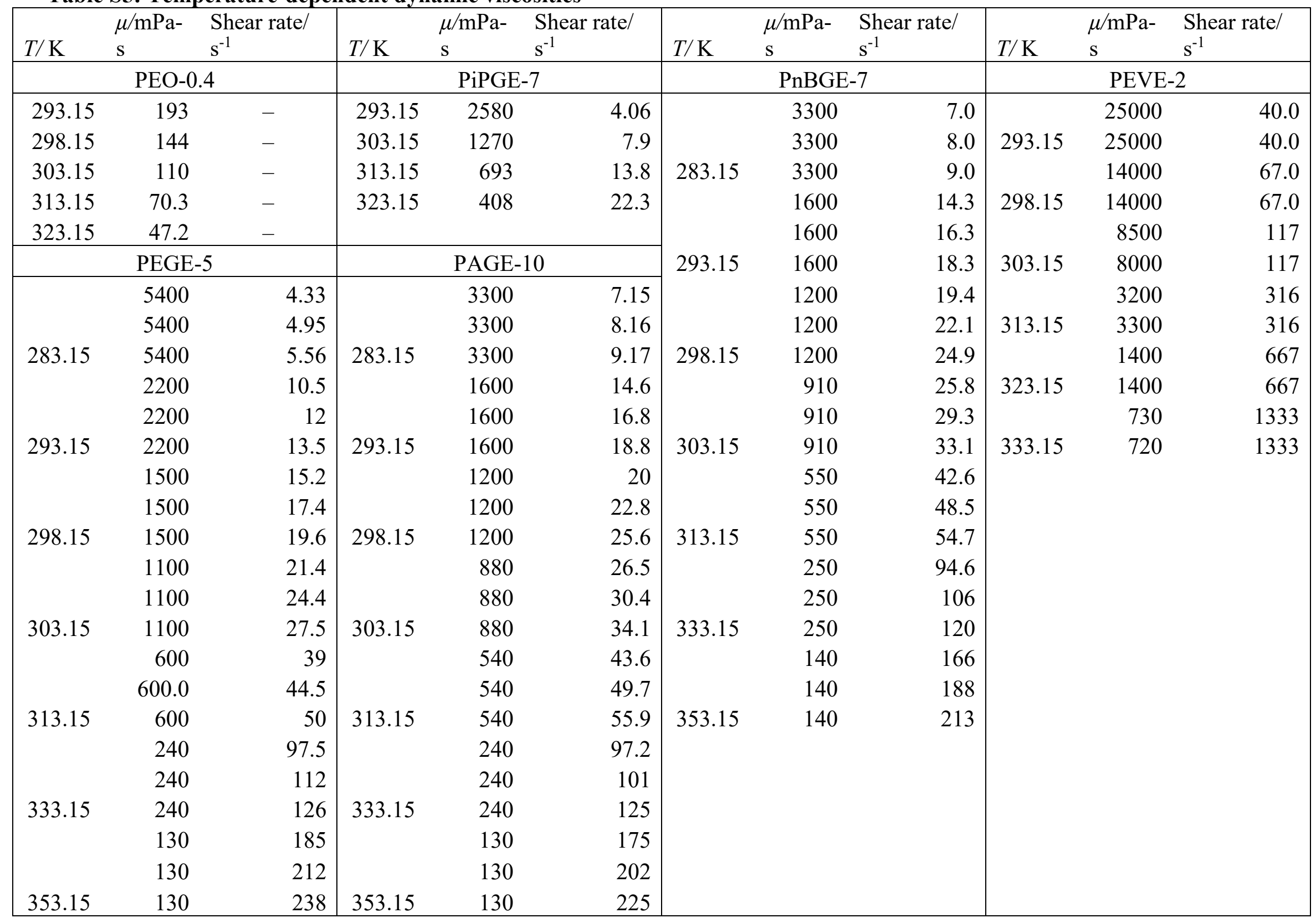


Standard uncertainties are $u(\mu)= \pm 0.5 \%$ and $u(T)= \pm 0.02$ for PEO-0.4 (rolling ball viscometer) and PiPGE-7 (SVM 2001) and $u(\mu)= \pm 7 \%$ and $u(T)$ $= \pm 0.1 \mathrm{~K}$ for all other polymers (Brookfield CAP2000) 


\section{References}

1. Anthony, J. L.; Maginn, E. J.; Brennecke, J. F., Solution thermodynamics of imidazolium-based ionic liquids and water. J. Phys. Chem. B. 2001, 105, (44), 10942-10949. 2. Macedonia, M. D.; Moore, D. D.; Maginn, E. J.; Olken, M. M., Adsorption studies of methane, ethane, and argon in the zeolie mordenite: molecular simulations and experiments. Langmuir 2000, 16, (8), 3823-3834.

3. Taylor, J. R., An Introduction to Error Analysis. 2 ed.; University Science Books: Sausalito, CA, USA, 1997.

4. $\quad$ Chirico, R. D.; Frenkel, M.; Magee, J. W.; Diky, V.; Muzny, C. D.; Kazakov, A. F.;

Kroenlein, K.; Abdulagatov, I.; Hardin, G. R.; Acree, J., Willam E.; Brennecke, J. F.; Brown, P. L.; Cummings, P. T.; de Loos, T. W.; Friend, D. G.; Goodwin, A. R. H.; Hansen, L. D.; Haynes, W. M.; Koga, N.; Mandelis, A.; Marsh, K. N.; Mathias, P. M.; McCabe, C.; O'Connell, J. P.; Pádua, A.; Rives, V.; Schick, C.; Trusler, J. P. M.; Vyazovkin, S.; Weir, R. D.; Wu, J., Improvement of Quality in Publication of Experimental Thermophysical Property Data: Challenges, Assessment Tools, Global Implementation, and Online Support. J. Chem. Eng. Data 2013, 58, 2699-2716. 